\title{
DIREITO NATURAL E SUA IMPORTÂNCIA NA SOLUÇÃO DE CONFLITOS PELA MEDIAÇÃO
}

\author{
Rozane da Rosa Cachapuz \\ Ana Paula Nacke Paulino** \\ Luciane Delalibera Bim**
}

\begin{abstract}
RESUMO: O direito natural pode ser considerado como a base valorativa e o balizador para a construção do direito positivo. Neste contexto, visualiza-se o quanto os valores e concepções do direito natural são importantes para a aplicação da mediação, técnica que procura enxergar não apenas o conflito, mas o indivíduo e as relações no âmbito conflituoso, visando a justiça em sua plenitude. Assim, através do método dedutivo, com pesquisas bibliográficas e, legislação pertinente, observou-se a importância da base principiológica e determinação do homem em sua essência, fornecidas pelo direito natural para a resolução de conflitos pela mediação.
\end{abstract}

Palavras-chave: Autocomposição; Conflito; Direito Natural; Justiça; Mediação.

\section{NATURAL LAW AND ITS IMPORTANCE IN SOLVING CONFLICTS BY MEDIATION}

\begin{abstract}
Natural law can be considered as the valuation basis and the guideline for construction of positive law. In this context, it's possible to see how important the values and conceptions of natural law are for the application of mediation, technique that seeks to see not only the conflict, but the individual and the relations in the conflictual scope, aiming at justice in its fullness. Thus, through the deductive method, with bibliographic research and, pertinent
\end{abstract}

\footnotetext{
* Doutora em Relações Internacionais, com ênfase em Direito de Família, pela Pontifícia Universidade Católica de São Paulo (PUC-SP). Mestre em Direito Negocial, Civil e Processual Civil pela Universidade Estadual de Londrina (UEL). Coordenadora do Curso de Pós-Graduação em Direito de Família e Sucessões: Teoria e Prática, na Universidade Estadual de Londrina (UEL). Coordenadora do Projeto de Pesquisa "Do Acesso à Justiça no Direito das Famílias", vinculado ao Programa de Mestrado e Doutorado em Direito Negocial da Universidade Estadual de Londrina (UEL). Docente na graduação e pós-graduação (Especialização, Mestrado e Doutorado) da Universidade Estadual de Londrina (UEL). Endereço: Rua Franklina Neves Ribas, n 210, Jardim Burle Marx, Londrina/PR, CEP 86047-770. E-mail: rozane_cachapuz@hotmail.com.

*** Mestranda em Direito Negocial pela Universidade Estadual de Londrina (UEL). Pós-graduada em Direito do Trabalho e Processo do Trabalho e em Direito de Família e Sucessões. Graduada em Direito pelo Centro Universitário Integrado de Campo Mourão/PR. Pesquisadora do Projeto de Pesquisa "Do Acesso à Justiça no Direito das Famílias", vinculado ao Mestrado e Doutorado em Direito Negocial da UEL e dos Projetos de Pesquisa "Acesso à Ordem Jurídica Justa" e "Mediação como Método Adequado na Resolução de Conflitos", ambos vinculados à Graduação em Direito do Centro Universitário Integrado. Advogada e professora. Endereço: Avenida Capitão Índio Bandeira, $\mathrm{n}^{\circ}$ 2021, Centro, Campo Mourão/PR, CEP 87300-005. E-mail: anapaulanacke@gmail.com.

**** Mestranda em Direito Negocial pela Universidade Estadual de Londrina (UEL). Pós-graduada em Direito Tributário na Damásio Educacional e em Direito Empresarial na Universidade Estadual de Londrina/ PR. Graduada em Direito pela Pontifícia Universidade Católica do Paraná (Campus Londrina). Pesquisadora no Projeto de Pesquisa "Do Acesso à Justiça no Direito das Famílias", vinculado ao Programa de Mestrado e Doutorado em Direito Negocial da Universidade Estadual de Londrina (UEL). Advogada. Endereço: Rua Tupi, n 329, apto 1602, Centro, Londrina/PR, CEP 86020-350. E-mail: lu_bim@hotmail.com.
} 
legislation, it was observed the importance of principiological basis and determination of man in essence, provided by natural law for the resolution of conflicts through mediation.

Keywords: Self-composition; Conflict; Natural law; Justice; Mediation.

\section{INTRODUÇÃO}

O positivismo jurídico ganhou força a partir do século XIX, mas até então a compreensão do fenômeno do direito estava ampla e significativamente embasada em uma tradição jusnaturalista. Ocorre que a expressão da ideia de direito natural na Modernidade transforma o próprio conceito de natureza, passando de cosmos ordenado, ou de Deus, para a racionalidade humana. $\mathrm{O}$ direito radicou seu fundamento na razão individual, identificada com a natureza humana. O homem ressignificado se livrou dos laços e regras sociais objetivamente definidos, abandonando sua condição de simples peça de uma engrenagem harmônica e assumindo sua condição de ser livre e autônomo, capaz de pensar e agir conforme sua determinação.

No mesmo sentido estabelece-se através do método dedutivo, com pesquisas em fontes bibliográficas, e legislação pertinente, que a mediação, que tem como um de seus princípios basilares a autonomia de vontade, em que, mais do que aplicar-se a lei positiva, é necessário analisar-se todo o contexto e observar-se as nuances indiretamente ligadas à controvérsia, o que normalmente justifica a utilização de valores e princípios oriundos do direito natural. Observa-se ainda a importância da base principiológica e determinação do homem em sua essência fornecidas pelo direito natural para a resolução de conflitos pela mediação, sendo insuficiente, em regra, a simples aplicação da norma posta, do direito positivo.

E é justamente na livre determinação do homem, corolário do estado democrático de direito, que surge o cenário para a aplicação de valores e supraprincípios que tem como embasamento o direito natural, pautados na justiça, na ética e na moral.

\section{DIREITO NATURAL}

O direito natural, ou jusnaturalismo, encontra suas bases ainda na antiguidade, sendo tema de numerosos debates e reflexões, por renomados estudiosos. Segundo Barretto e Bragato (2013, p. 31), este confundiu-se, de certa forma, com a própria história da Filosofia 
do Direito e é a mais antiga tentativa de compreensão teórica abrangente do Direito, que encontra validade em um sistema superior de normas ou princípios (direito ideal), decorrente de uma ordem jurídica natural.

\subsection{Conceito e concepções}

Embora a concepção de direito natural tenha assumido diversas formulações ao longo da história, possui a base comum que repousa em uma ordem normativa imanente e manifestada na natureza ou realidade. Assim, tem como "elemento comum unificador e identificador a ideia da existência de uma ordem normativa, imanente e manifestada na natureza ou na realidade, que é como que o paradigma, o modelo ou o arquétipo a que deve subordinar-se o direito positivo" (TEIXEIRA, 2006, p. 181).

Desta forma, a descoberta de que a natureza tinha leis próprias, que se diferenciariam das normas estabelecidas pela convenção entre os homens, se tornou condição necessária para o aparecimento da ideia do direito natural. Essa diferenciação entre esses dois tipos de lei iria se expressar na filosofia clássica pelos conceitos de physis - expressão da lei do mundo físico e natural, e de nomos, significando a lei humana (BARRETTO; BRAGATO, 2013, p. 31).

O pensamento jusnaturalista, segundo Teixeira (2006, p. 182), implica em quatro pressupostos: a) existe uma natureza permanente, constante e imutável; b) essa natureza contém intrinsecamente uma ordem normativa; c) o homem pode ascender ao conhecimento dessa ordem normativa; d) A ordem normativa natural imprime validade à ordem normativa humana, devendo aquela ser o modelo ou paradigma desta.

Assim, embora a função do Direito Natural seja unívoca - fundamentar axiologicamente o direito positivo e estabelecer um princípio para a sua validade - a concepção acerca do que seja a Natureza a que o Direito Natural se reportaria diverge bastante. Teixeira (2006, p. 183) divide a temática em três grandes concepções jusnaturalistas: Essencialista ou Substancialista, Formalista e Existencialista, sendo que a primeira se divide em três momentos distintos: Cosmológica, Teológica e Antropológica.

\subsubsection{Concepção essencialista ou substancialista}

A) Concepção cosmológica 
O Direito Natural Cosmológico ou Jusnaturalismo antigo remonta à antiguidade greco-romana, tendo o bem como realização última do ser humano. Não seria o prazer que move o homem, mas as suas necessidades, em uma ordem natural que determina a sua hierarquia e que remete para a constituição natural do ser, então seria bom o homem que realiza bem o trabalho que corresponde à sua natureza (BARRETTO; BRAGATO, 2013, p. $32)$.

A concepção cosmológica entende o Direito Natural relacionando-o à "ideia de natureza como ordem cósmica, que contém em si a sua própria lei, fonte da ordem em que se processam os movimentos dos corpos ou em que se articulam os seus elementos constitutivos essenciais" (TEIXEIRA, 2006, p. 191).

Conforme apontado, esta concepção deve-se especialmente aos gregos présocráticos, em que a natureza (physis) era a causa de movimento de todos os corpos (devir), e tem como expoentes Anaximandro e Heraclito, dentre outros.

\section{B) Concepção teológica}

Com a consolidação do Cristianismo na Europa, após a queda do Império Romano, a concepção grega cosmológica de natureza deu lugar ao entendimento de que é Deus, através de sua infinita sabedoria e onipotência, quem determina todas as ações e movimentos no cosmos (BARRETTO; BRAGATO, 2013, p. 32). A fase Teológica tem como expoentes Santo Agostinho e São Tomás de Aquino, dentre outros.

Santo Agostinho sustentou a ideia de que a ordem universal seria regida pela lei eterna, advinda de Deus, cujas ideias são os arquétipos eternos das coisas. A lei natural seria a "participação do homem na lei eterna e encontra-se impressa na alma humana" (TEIXEIRA, 2006, p. 196).

São Tomás de Aquino parte da indagação de a lei encontrar-se mais no âmbito da vontade ou da racionalidade. Entende ele que somente a razão pode ser regra ou medida, e como a lei é regra e medida das ações humanas, a lei irá depender da razão (BARRETTO; BRAGATO, 2013). Assim, a lei era uma descrição de uma razão prática que decorreria da própria natureza humana, logo, as leis humanas devem respeitar as naturais.

C) Concepção antropológica 
A fase antropológica ou contratualista baseia-se no pensamento pós-renascentista, racionalista e iluminista, tendo como expoentes Grócio, Hobbes, Espinosa, Puffendorf e Locke, dentre outros. Esta etapa retira a base do Direito Natural da compreensão divina e a repassa para a razão humana ou natureza racional do homem.

Embora o contratualismo não tenha rompido com a ideia do direito natural, contribuiu para questionar o entendimento de natureza no direito, perpassando por questionamentos e reflexões acerca do individualismo. As diversas escolas, embora possuam divergências, transitam pelo mesmo paradigma antropocêntrico, baseado na mesma forma de compreender a relação entre o indivíduo, a sociedade e o Estado: o indivíduo precede a sociedade e o Estado, que resultariam da necessidade dos homens em superar o estado de guerra ou o estado de natureza (BARRETTO; BRAGATO, 2013, p. 48).

Teixeira (2006, p. 200) aborda o pensamento contratualista, aduzindo que Grócio inaugura uma fase contratual como fonte do poder vinculante e legitimidade do direito positivo, o qual permanecerá até Kant (que terá um novo entendimento - formalista). Como a natureza humana é, eminentemente, social e racional (recta razão), o natural é que se agrupe e estabeleça as regras desta convivência, que devem, racionalmente, repousar nesta ordem natural de sociedade.

Assim, o indivíduo representa o núcleo das doutrinas contratualistas, pois reconhecese no homem a livre disposição de vontade, o que torna possível a realização do pacto e da consequente criação da sociedade civil. $\mathrm{O}$ contrato, assim, que dá origem ao Estado e às normas jurídicas, seria decorrente da vontade livre dos indivíduos.

\subsubsection{Concepção formalista}

Esta segunda concepção tem como base o pensamento kantiano, com significativa expressão nas ideias de Rudolf Stammler. Para esta corrente, o Direito Natural é formalmente permanente e imutável, porém, seu conteúdo material é variável e mutável ao longo das expressões histórico-culturais.

Explana Teixeira (2006, p. 216) que Kant entendia ser impossível ao intelecto humano chegar à essência das coisas, sendo-lhe possível apenas a captura do mundo dos fenômenos, o que implica que não se pode alcançar qualquer conhecimento da essência ou da 
natureza do homem nem procurar fundar nela qualquer normatividade, havendo apenas que ter em conta as formas a priori da razão, assim a ideia do direito seria unicamente formal.

Já Stammler, também citado pelo autor (TEIXEIRA, 2006, p. 217) diferencia o que é "conceito" de direito de "ideia" de Direito. Conceito pressupõe um todo ordenado de regras, que independem da verificação de fenômenos jurídicos. De outro lado, a ideia de Direito implica em refletir acerca de sua finalidade - a justiça, o que conduz a uma concepção de Direito Natural de conteúdo variável no tempo e no espaço.

\subsubsection{Concepção existencialista}

Esta concepção opõe-se às concepções anteriores por entender que não existe qualquer essência, substância ou natureza humanas, comum a todos os homens e dada previamente, pois a existência precederia a essência, e seria aquela um resultado entre a natureza das coisas e a vocação do homem.

De acordo com Teixeira (2006, p. 221), Delfim Santos entendia que o homem não possui uma natureza previamente dada, mas a sua existência possibilita a contínua construção do ser, em que ocorre a incidência normativa, não devendo existir diferenciação entre Direito Natural e Positivo. Já Welzel entendia que haveria o Princípio da Autonomia moral do ser humano, que seria o único a garantir um conteúdo valorativo ao Direito, o que condicionaria o seu conteúdo valorativo às diversas realidades histórico-sociais.

Werner Maihofer e Erich Fechner mantém a noção de Direito Natural, mas entendido agora como "esboço antecipado ou projecto de determinação histórica do homem por si próprio, cujo fundamento estará não já na essência pré-existente do homem, mas sim na sua existência no mundo em que ele se projeta historicamente segundo as determinações da sua essência" (TEIXEIRA, 2006, p. 222).

Conforme será explanado adiante, principalmente esta concepção, que estabelece a ideia de um direito natural embasado não em uma essência pré-existente e padrão do homem, mas sim construída considerando-se o seu contexto, a sua história e os seus valores, bem como na autonomia moral do indivíduo, capaz de garantir um conteúdo valorativo ao direito, coaduna-se amplamente com os pressupostos básicos da mediação.

\subsection{Contribuições do direito natural para o direito contemporâneo}


O jusnaturalismo ou direito natural, conforme já abordado, é a corrente de pensamento jurídico-filosófica que tem como premissa uma norma de conduta intersubjetiva universalmente válida e imutável, base pré-existente do direito positivo, necessária para a regulação da sociedade humana, principalmente no que se refere aos conflitos entre o Estado e a sociedade.

Por certo que não faltaram críticos ao direito natural no decorrer da história. Teixeira (2006, p. 230-232), para justificar a importância do direito natural, elege dois críticos do jusnaturalismo, procurando rebater seus apontamentos.

Quanto à crítica de Kelsen - que afirma ser esta uma doutrina idealista-dualista, não se tratando de verdadeiro direito, pois as leis naturais padeceriam de falta de eficácia, já que se assentam em fatos naturais sem cogência alguma - o autor afirma que, em que pese o Jusnaturalismo ser, de fato, uma doutrina dualista, muitas das teorias do Juspositivismo são, igualmente, dualistas, inclusive, a de Kelsen, que não consegue explicar a origem de sua norma fundamental.

Ainda, afirma que o idealismo jusnaturalista, longe de refutar uma busca axiológica constante, repousa na diferenciação entre o "ser" e o "dever ser", pois não se pode ter uma visão reducionista da realidade, fatos correspondem a normas. No tocante ao argumento de Kelsen de que o Direito Natural deriva de uma base metafísica, o autor concorda, pois o fundamento realmente não repousa na lei, mas na busca constante de uma justiça. Ressalta ele que a doutrina naturalista tem estado na base de vários movimentos revolucionários que geraram a luta por direitos humanos.

Quanto às críticas de Bobbio - de que mesmo que houvesse um conceito unânime acerca de natureza, o conceito de justo e de injusto não trariam concepções universais, originando o dualismo na interpretação - o autor afirma que o Direito Natural, de fato, por não ser reiteradamente respeitado, se consagra, cada vez mais, como um ideal a ser atingido, sagrando-se como este feixe dos valores buscados pela alma inquieta humana.

Importante observar que a concepção jusnaturalista foi o resultado de transformações econômicas e sociais que impuseram mudanças na concepção de poder do Estado, que passou a ser compreendido como uma instituição criada através do consentimento dos indivíduos através do contrato social. O declínio das relações feudais de produção, desenvolvimento econômico da burguesia, a Reforma Protestante, as revoltas camponesas e as guerras 
ocorridas durante o processo de formação do capitalismo propiciaram uma nova situação social. (SOUSA, 1977, p. 45).

Desta forma, percebe-se que o direito natural está no cerne de muitas revoluções e lutas por direitos, sobretudo os direitos individuais. No que diz respeito ao direito positivo, serve de embasamento especialmente para a parte principiológica, estabelecendo critérios axiológicos relacionados à moralidade, eticidade e justiça, pois as ideias trazidas pelo jusnaturalismo introduziram na sociedade princípios de caráter universal, de ordem moral e racional, possibilitando a análise do bem e do mal nas leis e ações estatais, sendo possível determinar-se leis justas ou injustas.

Para Sousa, negar o direito natural seria negar o princípio absoluto da justiça, sendo o direito natural o único critério para impor limites ao legislador, coibindo o seu arbítrio:

\begin{abstract}
Ora, o direito ou é objeto da justiça, ou é simples produtos das flutuações do arbítrio legislativo. [...] Eliminado o conceito de direito natural, não há nenhuma razão suficiente para que o legislador deva promover o bem comum, os súditos devam obedecer à autoridade, os contratos devam ser observados. É por recuarem ante a inexorabilidade de tais consequências, que os próprios positivistas afirmam, muitas vezes, a existência de um princípio universal e permanente, superior à vontade humana, e que constitui o fundamento da ordem jurídica (SOUSA, 1977, p. 46-47).
\end{abstract}

A incorporação de princípios gerais relacionados à moralidade, eticidade e justiça ao ordenamento jurídico, como base para a atuação do poder estatal, garante a ampliação do horizonte normativo, no campo da hermêutica, criando o aspecto atemporal e interpretativo das normas jurídicas, indo além da subsunção da lei ao fato concreto.

Para Teixeira (2006, p. 248-250, há sim um dualismo no jusnaturalismo, e por isso impõe-se a necessidade de se pensar o direito positivo e o direito natural, pois um não nega o outro, mas sim se complementam. Para o autor, há um fundamento que transcende ao próprio Direito, fortemente imbuído de caráter axiológico, todavia, não encontra respaldo na ideia de "natureza das coisas", mas na ideia de justiça, fundamento e ideal do Direito.

\title{
3 MEDIAÇÃO
}

Conforme repassado pelas concepções do direito natural, observa-se que o jusnaturalismo foi o resultado de transformações econômicas e sociais que impuseram mudanças na concepção de poder do Estado, que passou a ser compreendido como uma instituição criada através do consentimento dos indivíduos. O direito natural, assim, 
independe do Estado ou de Leis, por isso é considerado autônomo, pois inerente ao ser humano, possuindo caráter universal, imutável e atemporal.

Um dos princípios da lei natural é a obrigação de fazer o bem e evitar o mal. É esse princípio o fundamento da obrigação moral e também o fundamento racional do direito. Enquanto a moral se ocupa com todo o bem, o direito tem por objeto a parte do bem que constitui o justo (SOUSA, 1977, p. 47-48).

O senso comum deve servir de ponto de partida a qualquer sistema filosófico para atingir a verdade e, estando a origem do conceito do direito natural nas distinções feitas pelo senso comum (SOUSA, 1977, p. 52), podemos trazer à baila o instituto da mediação como forma de resolução dos impasses havidos em sociedade. Desde que se admita que o direito se reduz à justiça e a justiça se reduz ao bem, deve-se necessariamente admitir que há um direito natural, e é isso que busca a mediação, uma pacificação social e fortalecimento do diálogo.

\subsection{Abrangência do instituto da mediação}

Os meios de solução de conflitos, em especial a mediação, estão presentes no Brasil há mais de 30 anos e já vinham sendo estudados por especialistas, entretanto, foi especialmente com o advento do Novo Código de Processo Civil - Lei $\mathrm{n}^{\mathrm{o}}$ 13.105/15 (BRASIL, 2015) e a Lei de Mediação - Lei no 13.140/15 (BRASIL, 2015), é que se deu maior relevância para este instituto.

Desta forma, tecendo de modo claro o objetivo e a finalidade da mediação, o parágrafo único do artigo $1^{\circ}$ da Lei de Mediação a define como "atividade técnica exercida por terceiro imparcial sem poder decisório, que, escolhido ou aceito pelas partes, as auxilia e estimula a identificar ou desenvolver soluções consensuais para a controvérsia”.

Em outras palavras, a mediação é um dos instrumentos de pacificação de natureza autocompositiva e voluntária, na qual um terceiro, imparcial, atua como um facilitador do processo de retomada do diálogo entre as partes, fazendo com que elas encontrem uma solução para o conflito. Roberto Portugal Bacellar (1999, p. 128), traz que a mediação representa um meio alternativo de solução de controvérsias na medida em que se insere em um modelo consensual onde não existe a característica de conflituosidade do modelo tradicional de jurisdição. 
Também de acordo com os ensinamentos de Rozane da Rosa Cachapuz (2005, p. 28), a mediação é considerada "um meio extrajudicial de resolução de conflitos, onde um terceiro é chamado para encaminhar as partes a chegarem a uma solução ou acordo". Em complemento, segundo a doutrina de Luiz Alberto Warat (1999, p. 29), a mediação é uma forma de resolução dos conflitos sociais e jurídicos, uma forma na qual o intuito de satisfação do desejo substitui a aplicação coercitiva e terceirizada de uma sanção legal.

Por ser a mediação um processo de facilitação da comunicação, através da qual é possível proporcionar uma intervenção mais rápida e menos desgastante, é que acaba sendo muito eficiente em várias searas do direito, pois com as técnicas empregadas neste procedimento, as partes ficam mais propensas a ouvir o outro lado e, consequentemente, a chegar a um acordo mutuamente, além de colaborar com o fortalecimento do diálogo.

Diante desse escopo maior da mediação, que permite a preservação das relações sociais, ela acaba direcionada preferencialmente para as situações em que existe um vínculo jurídico ou pessoal continuado entre os envolvidos no conflito.

A mediação, então, é apropriada para questões que tenham passado, presente e futuro, identificando soluções que busquem preservar as relações entre as partes por meio de um consenso, sendo um degrau a mais para se chegar a uma pacificação social. Destina-se, de certa forma, sendo ela judicial ou extrajudicial, a buscar uma democracia mais participativa, em que a autonomia privada é assegurada, ultrapassando a ideia de que para haver um verdadeiro Estado de Direito é necessário apenas o direito positivo, quando na verdade, faz-se necessário o dualismo direito natural e direito positivo.

\subsection{A mediação como instrumento do Estado Democrático de Direito}

Não é suficiente que os cidadãos afirmem o seu poder através de negociações baseadas apenas no interesse de grupos particulares. Portanto, uma reconstrução democrática da esfera pública se dá por meio de perspectivas emancipatórias que contemplem a implementação de procedimentos racionais, discursivos, participativos e pluralistas.

O Estado de Direito tornou-se a grande aspiração daqueles que querem ver respeitados os direitos humanos. Pois ele essencialmente significa a submissão do Estado à ordem jurídica, de maneira a salvaguardar as liberdades, evitando as arbitrariedades do poder (SOUSA, 1977, p. 125). 
Nesse contexto, o instituto da mediação como instrumento de solução de conflitos, em face de seu procedimento fundamentado na razão comunicativa, auxilia na busca pela solidificação do Estado Democrático de Direito. A utilização de mecanismos pacificadores voltados a solucionar os impasses da vida em sociedade, como a mediação, evidencia a possibilidade da interlocução política daqueles que são afetados pela gestão privada e pública.

É no convívio da vida humana que se produzem as mais variadas espécies de relações humanas, caracterizadas assim, por meio da convivência, identificadas também pelos atos de competição, de cooperação ou de indiferença entre as pessoas. Tal agir, deste modo, é fruto da liberdade (GOMES, 2011, p. 207).

Por ser a mediação um processo de facilitação da comunicação, através da qual é possível proporcionar uma intervenção mais rápida e menos desgastante, em virtude das técnicas empregadas neste procedimento, as partes ficam mais propensas a ouvir o outro lado e consequentemente chegar a um acordo mutuamente, com soluções voltadas para o diálogo, preservando-se assim, as relações.

Este é, pois, um modo de se orientar a convivência, o que significa, apontar direção e caminhos que conduzam a objetivos assumidos como metas realizadoras de valores a serem alcançadas por todos os participantes do referido convívio. Segundo o pensamento democrático, construído a partir dos valores que dão sentido à democracia, começando pelo princípio da dignidade humana, ninguém deve ser excluído deste convívio que somente se concretiza mediante a participação de todos, visto que os valores devem ser compartilhados por todos (GOMES, 2011, p. 209-210).

A mediação, desta maneira, dá ao indivíduo a autonomia privada em escolher como ele vai querer solucionar um conflito existente na sua vida em sociedade ou até mesmo evitálo num futuro próximo, fortalecendo o diálogo dos envolvidos. A visão individualista acabou fundindo-se para uma concepção social, uma vez que houve a necessidade de preservar os interesses dos indivíduos dentro de um grupo e da sociedade, conferindo a determinados entes o poder de acionar a jurisdição, e fazer cumprir tais deveres (BELINETTI, 2000, p. 125).

O novo paradigma do direito, baseado na democracia processual e na política deliberativa, exige que a discussão argumentada predomine sobre a decisão voluntária do poder, o que é, deste modo, proporcionado pela mediação. A razão processual convoca a prática do entendimento consensual por meio do diálogo. 
Com o fim de concretizar o Estado Democrático de Direito, o professor Sérgio Alves Gomes (2011, p. 213), assim assevera:

Para concretizá-lo como superação de paradigmas anteriores, faz-se necessário
resgatar, em linguagem adequada aos novos tempos, ensinamentos que contribuem
na percepção do modo de ser humano: um ser que não se rege pelo automatismo por
ser dotado de liberdade e que se move, antes de tudo, pelo anseio produzido por uma
gama de valores. Pretende-se que estes sejam vivenciados e compatibilizados nos
espaços da convivência humana que se quer fraterna. E que, por isso, não deve
excluir ninguém das possibilidades de participação. Isso porque, no novo modo de
se conceber a Democracia, almeja-se que seja merecida a qualificação de
Democracia participativa. Isso exige dela a inclusão do outro e, para tanto, há de ser
também uma forma superadora de modelos democráticos que se mostraram
incapazes de realizar tal intento.

O tratamento de conflitos mediante a utilização da mediação pode acontecer em face de uma pluralidade de técnicas, e os contextos/áreas nos quais é possível aplicá-la são vários. Todos possuem como base "o princípio de religar aquilo que se rompeu, restabelecendo uma relação para, na continuidade, tratar o conflito que deu origem ao rompimento", através da comunicação (SPENGLER, 2010, p. 319), configurando como solução adequada de conflitos, a fim de que a implementação e prática de tal instrumento desenvolva uma cultura pacífica, estimulando atitudes dialógicas e cooperativas, com vistas ao bem comum da sociedade, buscado na democracia participativa.

Tem-se, desta maneira, que o Estado de direito supõe necessariamente o direito natural. A subordinação do Estado à ordem jurídica só será verdadeiramente eficaz, mediante uma condição indispensável: que se reconheça um critério objetivo de justiça, transcendente em relação ao direito positivo e do qual este depende, por isso, a importância do direito natural aliado ao instituto da mediação como solução de conflitos dentro da vida em sociedade.

\section{O DiReito NATURAL AliAdo À MEdiAção COMO SOLUÇÃo DE CONFLITOS}

Anteriormente, o Direito Natural tinha o papel de regular o convívio social dos homens, que não necessitavam de leis escritas, sendo, pois, uma visão objetiva. Com o surgimento do Direito Positivo, sua função passa a ser uma forma de contrapeso à atividade legiferante do Estado, fornecendo subsídios para a reivindicação de direitos pelos cidadãos. E é 
neste último aspecto que reside o caráter subjetivo do Direito Natural, que jamais deixou de existir.

Uma sociedade precisa naturalmente criar acordos para evitar conflitos, devendo esses acordos serem espontâneos, naturais, visto que muitas vezes, a coerção acaba sendo uma forma de semear o conflito, e não o resolver.

Ao Estado, desta forma, cumpre respeitar e tutelar não só os direitos dos indivíduos, mas também os das famílias e dos demais corpos sociais constitutivos da sociedade política e cuja autonomia deve ser assegurada. A solução, desta forma, está em se buscar normas no plano de um direito natural (SOUSA, 1977, p. 126).

É preciso, pois, distinguir entre o modelo pensado e desejado, positivado no texto constitucional, e a realidade concreta vivida e percebida diuturnamente em relação ao que está posto juridicamente (GOMES, 2011, p. 240).

Nesse interim, não é razoável que o homem queira abdicar das prerrogativas de sua própria natureza, refutando o Direito Natural, tentando libertar-se das leis morais natas, desprezando o senso de justiça que é peculiar ao ser humano. Sergio Alves Gomes (2011, p. 240), traz que "por maiores que sejam os esforços para a concretização dos valores democráticos, estes sempre estarão a exigir aperfeiçoamentos das condutas reais em face do modelo idealizado e positivado no texto da Constituição". A mantença dessas características se faz ainda mais necessária diante de institutos como o da mediação de conflitos, posto que são ferramentas categóricas para a participação dos envolvidos em que esperam soluções eficazes de fato, já que a mediação é uma forma de solução de conflito em que o acordo final nasce a partir de um entendimento amigável, maduro.

Portanto, por mais que atualmente a mediação venha regulamentada em lei, a respeito de sua operacionalidade, princípios e forma de aplicabilidade, esta independe de conhecimento das leis positivadas, embora esteja limitada por elas, para colocar fim ao litígio, ou evitar que o mesmo ocorra. Todavia, as partes só poderão acordar sobre solução que não ultrapasse os limites presentes no Direito Positivo.

Advém das próprias partes, ou seja, dos mediados, possuindo eles apenas auxílio do mediador no que tange à facilitação do diálogo na busca da solução do conflito. As partes então, por força do diálogo, conseguem, racionalmente, alcançar um acordo que ponha fim às suas divergências, e ainda, até mesmo manter a mesma relação existente antes do conflito, após terem resolvido pacificamente o impasse, com o auxílio da mediação. 
Deste modo, negar o direito natural, mais do que simples erro, é inconsciência de suas aptidões e potencialidades, ignorância de sua vocação criadora e transformadora, temor de mobilizar sua capacidade de superação e ultrapassagem. Antes de repudiar o Direito Natural, abjuram-se os valores formativos da intelectualidade humana. Afasta a ideia, em favor da simples imagem, instala-se a aridez mental, fonte da desolação e do pessimismo. (VASCONCELOS, 1998, p. 29).

Verifica-se, assim, que para a mediação atingir seu fim, não se pode falar na aplicação fria da norma positiva, mas, antes, pensar-se no diálogo, em técnicas de comunicação, achar o pontapé inicial do conflito, a libertação de rancores. Faz-se imprescindível que, acima de tudo, inicialmente, os mediados estejam abertos ao diálogo, independentemente de ter conhecimento formal das leis, buscando seu senso interior de justiça e harmonia.

Independente das regras impostas pelo Direito Positivo, na mediação, todos os envolvidos, até mesmo aqueles que auxiliarão, precisam buscar os valores morais natos, e defendidos pelo Direito Natural. Percebe-se, portanto, que o Direito Natural deve ser visto como fonte rica para a solução de conflitos pela mediação.

Nesse passo, uma importante contribuição do Direito Natural foi dar conformação aos direitos e garantias fundamentais do homem, objetivando preservar sua dignidade, mesmo que passado anos, o direito natural ganhou nova abordagem de acordo com os interesses dos cidadãos:

Obra humana, projeção de sua natureza, o Direito Natural tornou-se elemento imprescindível a toda especulação sobre o Direito. Tem sido assim desde as origens mais remotas da Filosofia do Direito, e não há indício de nenhuma mudança para o futuro. A não ser que o homem perca sua identidade (VASCONCELOS, 1998, p. 31).

Aliada ao direito natural, a mediação possui viés democrático, visto que a democracia em si, em especial a participativa, pretende construir uma sociedade regida pelo entendimento, solidariedade e pelo mútuo respeito entre as pessoas, ordenada por princípios de Justiça. Uma sociedade em que cada ser humano goze de respeito como pessoa ao invés de ser coisificado (GOMES, 2011, p. 254).

Dar vida à Constituição do Estado Democrático de Direito, respeitando-a mediante a efetiva concretização de suas determinações, equivale a avançar em direção a uma convivência menos brutal, graças ao respeito a limites que possibilitam a distinção entre 
barbárie e civilização, ódio e amor, justo e injusto (GOMES, 2011, p. 417). Neste sentido, os elementos de caráter geral do direito natural se mostram alinhados à sociedade contemporânea, globalizada e massificada, que vive em constante mudança, desconstruindo paradigmas, descobrindo novas tecnologias e repleta de novos fatos sociais.

Desta forma, é possível afirmar que quanto maior a complexidade da relação jurídica existente no seio da sociedade, maior será a importância da observância de princípios éticos, democráticos e justos, capazes de flexibilizar a compreensão da norma, o que justifica de forma ampla e clara a importância do direito natural e suas concepções na resolução de conflitos através da mediação.

\section{CONCLUSÃO}

As influências trazidas pelo jusnaturalismo introduziram na sociedade princípios de caráter universal, de ordem moral e racional, possibilitando a análise do bem e do mal das leis e das ações estatais, leis justas ou injustas. O jusnaturalismo apresentou os critérios axiológicos relacionados à moralidade, eticidade e justiça, que foram incorporados na norma posta, principalmente na positivação de princípios gerais e fundamentais do direito nas Constituições. Pode-se observar, desta forma, que o direito natural é o único critério para impor limites ao legislador, coibindo o seu arbítrio, o que se aplicaria em tempos atuais.

No contexto pós-positivista o Direito tem buscado aliar os aspectos positivos e contributivos do direito natural ao ordenamento jurídico normativo coexistente. Contemporaneamente, na vida em sociedade, é latente a formação crescente de inúmeros conflitos, das mais diversificadas formas que aparecem e que na grande maioria das vezes, poderiam ser evitados ou solucionados pacificamente.

Desta forma, a mediação, como forma de dirimir conflitos surgidos dentro das mais diversas áreas, traduz a ideia que o direito natural busca, qual seja, chegar em um senso comum que deve servir de ponto de partida, para atingir não só a verdade, mas por consequência, fortalecer laços, restabelecer o diálogo. Posto que, desde que se admite que o direito se reduz à justiça e a justiça se reduz ao bem, deve-se necessariamente admitir que há um direito natural, para que então também haja um verdadeiro Estado Democrático de Direito. 
Assim, uma importante contribuição do Direito Natural foi dar confirmação aos direitos e garantias fundamentais do homem, e mesmo que o direito positivo seja uma via importante para manter e resolver as relações entre as pessoas de uma sociedade, mantendo-se a ordem e segurança nas mesmas, não há como deixar de reconhecer que estas normas positivas vão se tornando obsoletas, devido ao dinamismo que envolve as relações, sendo este um processo histórico natural.

Faz-se imprescindível que haja uma atualização constante das regras e da forma de manutenção das relações, dando ainda mais valor à autonomia privada das partes, como é o caso da mediação, onde haverá, desta maneira, a incorporação dos fatos e dos valores recentes nascidos em decorrência do próprio progresso da sociedade, mas sempre obedecendo aos objetivos principais da convivência humana, quais seja, de justiça e paz, valores que o próprio direito natural traduz.

\section{REFERÊNCIAS BIBLIOGRÁFICAS}

BACELLAR, Roberto Portugal. A mediação no contexto dos modelos consensuais de resolução de conflitos. Revista de Processo, São Paulo: n. 95, p. 122-134, jul./set. 1999, p. 128.

BARRETO, Vicente de Paulo; BRAGATO, Fernanda Frizzo. Leituras de Filosofia do Direito. Curitiba: Juruá, 2013 (cap. II - Fundamentos da Cultura Jurídica Ocidental- p. 31 a 60).

BELINETTI, Luiz Fernando. Ações Coletivas: um tema a ser ainda enfrentado na reforma do processo civil brasileiro. A relação jurídica e as condições da ação nas ações coletivas. Revista de Processo n. ${ }^{\circ}$ 98, ano 25, p. 125-132, abr/jun, 2000.

BRASIL, Código de Processo Civil. Diário Oficial da União, Brasília, 17 mar. 2015. Disponível em: <http://www.planalto.gov.br/ccivil_03/_ato2015-2018/2015/lei/113105.htm>. Acesso em: 22 jan. 2021.

BRASIL. Lei $n^{\circ}$ 13.140/15. Dispõe sobre a mediação entre particulares como meio de solução de controvérsias e sobre a autocomposição de conflitos no âmbito da administração pública; altera a Lei $n^{\circ}$ 9.469, de 10 de julho de 1997, e o Decreto $n^{\circ} 70.235$, de 6 de março de 1972; e revoga o $\S 2^{\circ}$ do art. $6^{\circ}$ da Lei ${ }^{\circ} 9.469$, de 10 de julho de 1997. Diário Oficial da União, Brasília, 29 jun. 2015. Disponível em: <http://www.planalto.gov.br/ccivil_03/_ato20152018/2015/lei/113140.htm>. Acesso em: 22 jan. 2021.

CACHAPUZ, Rozane da Rosa. Mediação nos conflitos \& direito de família. Curitiba: Juruá, 2005, p. 28.

GOMES, Sergio Alves. Hermenêutica constitucional: um contributo à construção do Estado Democrático de Direito. $1^{\text {a }}$ ed. Curitiba: Juruá, 2011. 
SOUZA, José Pedro Galvão. Direito Natural, Direito Positivo e Estado de Direito. São Paulo: Revista dos Tribunais, 1977 (capítulos III, IV e VIII - p. 46 a 70; 125 a 151).

SPENGLER, Fabiana Marion. Da jurisdição à mediação: por uma outra cultura no tratamento dos conflitos. Ijuí: Unijuí, 2010.

TEIXEIRA, António Braz. Sentido e Valor do Direito: Introdução à Filosofia Jurídica $3^{\text {a }}$ ed. Lisboa: Imprensa Nacional - Casa da Moeda, 2006 (parte II, cap. I: O problema do direito natural- pgs. 179 a 250).

VASCONCELOS, Arnaldo. Direito, humanismo e democracia. São Paulo: Malheiros, 1998.

WARAT, Luiz Alberto. Ecologia, Psicanálise e Mediação. Em nome do acordo. 2 ed. Argentina: Almed, 1999. 